\title{
Asymmetric Dimethylarginine Attenuates the Association of Melatonin Secretion With Night-Time Blood Pressure and Dipping in Elderly Individuals - The HEIJO-KYO Cohort -
}

\author{
Kenji Obayashi, MD, PhD; Keigo Saeki, MD, PhD; Norio Kurumatani, MD, PhD
}

\begin{abstract}
Background: Melatonin decreases night-time blood pressure (BP) by increasing nitric oxide (NO) in endothelial cells. Whether serum asymmetric dimethylarginine (ADMA), a major endogenous competitive inhibitor of endothelial NO synthase, attenuates the association of melatonin with night-time BP and dipping in humans is unclear.
\end{abstract}

\begin{abstract}
Methods and Results: In this cross-sectional study of 852 community-based elderly individuals, serum ADMA, overnight urinary 6-sulfatoxymelatonin excretion (UME), and ambulatory BP were measured. Mean ADMA was $0.46 \pm 0.06 \mu \mathrm{mol} / \mathrm{L}$. In the low-ADMA group $(\mathrm{n}=451)$, crude OR for nocturnal hypertension $(\mathrm{NH})$ and non-dipper significantly decreased with a quartile increase in UME ( $P=0.023$ and 0.001 , respectively), but these associations were not observed in the high-ADMA group $(n=401)$. Higher UME was significantly and inversely associated with adjusted OR for NH and non-dipper in the low-ADMA group (Q1, 1.00 and 1.00; Q2, 0.92 and 0.74; Q3, 0.57 and 0.51; $\mathrm{Q} 4,0.48$ and $0.40 ; \mathrm{P}=0.004$ and 0.002 , respectively) but not in the high-ADMA group ( $\mathrm{P}=0.75$ and 0.12 , respectively). These association trends were also observed on continuous variable analysis (low ADMA, P=0.031 and 0.003; high ADMA, $\mathrm{P}=0.52$ and 0.13 ; respectively).
\end{abstract}

Conclusions: ADMA attenuates the association of endogenous melatonin with night-time BP and dipping in the general elderly population. (Circ J 2014; 78: 2908-2914)

Key Words: Asymmetric dimethylarginine; Blood pressure; Melatonin; Nocturnal hypertension; Non-dipper

I thas been recognized that night-time blood pressure (BP) and nocturnal BP fall (dipping) are better predictors of cardiovascular disease and mortality than daytime and office BP. ${ }^{1-3}$ Increased night-time BP (nocturnal hypertension, $\mathrm{NH}$ ) and the lack of dipping (non-dipper) are both related to a high risk of target organ damage and cardiovascular events. ${ }^{1,4,5}$

Melatonin secretion follows a circadian rhythm, with almost all production at night, and its receptors have been found in central and peripheral tissues, including endothelial cells. ${ }^{6-8}$ Melatonin increases endothelium-derived nitric oxide (eNO) that decreases vascular tone and arterial BP.9,10 Several clinical trials have suggested that oral melatonin lowers night-time BP. ${ }^{11,12}$ In addition, endogenous melatonin, which is present at considerably lower levels than pharmacological melatonin, is associated with non-dipper and NH. ${ }^{13-15}$ Thus, increased eNO induced by melatonin can partially explain the enhanced decrease in night-time BP and increase in dipping.

Asymmetric dimethylarginine (ADMA) is a major endogenous competitive inhibitor of NO synthase (NOS) that controls the bioavailability of eNO. This modified amino acid is derived from hydrolysis of post-translationally methylated proteins and is partly cleared by renal excretion. ${ }^{16,17}$ ADMA is elevated to levels that can inhibit NOS activity in individuals without renal failure. ${ }^{18}$ ADMA may increase as a result of the reduced activity of dimethylarginine dimethylaminohydrolase (DDAH), which hydrolyses ADMA to dimethylamine and L-citrulline. DDAH may be inactivated by atherosclerotic risk factors, including aging, diabetes, and oxidative stress. ${ }^{19}$

We hypothesized that melatonin secretion may be associated with $\mathrm{NH}$ and with non-dipper in individuals with low serum ADMA but that the association of melatonin with night-time BP and dipping may be attenuated in those with high serum ADMA. Associations between ADMA, melatonin secretion, and ambulatory BP (ABP), however, have not been explored in humans. To determine these associations, we conducted a cross-sectional study that included 852 community-based elderly individuals.

Received May 30, 2014; revised manuscript received August 26, 2014; accepted September 8, 2014; released online October 31 , 2014

Time for primary review: 19 days

Department of Community Health and Epidemiology, Nara Medical University School of Medicine, Kashihara, Japan

Mailing address: Kenji Obayashi, MD, PhD, Department of Community Health and Epidemiology, Nara Medical University School of Medicine, 840 Shijocho, Kashihara 634-8521, Japan. E-mail: obayashi@ naramed-u.ac.jp

ISSN-1346-9843 doi:10.1253/circj.CJ-14-0613

All rights are reserved to the Japanese Circulation Society. For permissions, please e-mail: cj@j-circ.or.jp 


\begin{tabular}{|c|c|c|c|c|c|c|}
\hline \multirow{2}{*}{ Variables } & \multicolumn{2}{|c|}{ Night-time BP } & \multicolumn{2}{|c|}{ Dipping } & \multicolumn{2}{|c|}{ ADMA } \\
\hline & Non-NH & NH & Dipper & Non-dipper & Low & High \\
\hline No. participants & 452 & 400 & 588 & 264 & 451 & 401 \\
\hline \multicolumn{7}{|l|}{ Basic and clinical parameters } \\
\hline Age (years) & $71.1 \pm 6.8$ & $73.1 \pm 7.1^{\star *}$ & $71.4 \pm 6.8$ & $73.6 \pm 7.2^{* *}$ & $70.6 \pm 6.4$ & $73.7 \pm 7.4^{\star *}$ \\
\hline Male & $192(42.5)$ & $233(58.3)^{\star *}$ & $288(49.0)$ & $137(51.9)$ & $212(47.0)$ & $213(53.1)$ \\
\hline $\mathrm{BMI}\left(\mathrm{kg} / \mathrm{m}^{2}\right)$ & $22.9 \pm 3.1$ & $23.4 \pm 3.1^{\star}$ & $23.1 \pm 2.9$ & $23.2 \pm 3.4$ & $23.0 \pm 3.2$ & $23.2 \pm 2.9$ \\
\hline Current smoker & $11(2.4)$ & $34(8.5)^{\star \star}$ & $26(4.4)$ & $19(7.2)$ & $19(4.2)$ & $26(6.5)$ \\
\hline Antihypertensive drug use & $187(41.4)$ & $191(47.8)$ & $242(41.2)$ & $136(51.5)^{\star \star}$ & $188(41.7)$ & $190(47.4)$ \\
\hline Diabetes & $47(10.4)$ & $54(13.5)$ & $59(10.0)$ & $42(15.9)^{\star}$ & $49(10.9)$ & $52(13.0)$ \\
\hline eGFR $\left(\mathrm{ml} \cdot \mathrm{min}^{-1} \cdot 1.73 \mathrm{~m}^{-2}\right)$ & $73.5 \pm 14.0$ & $70.6 \pm 15.6^{\star \star}$ & $73.0 \pm 13.9$ & $70.2 \pm 16.7^{\star}$ & $73.9 \pm 13.7$ & $70.2 \pm 15.9^{\star *}$ \\
\hline ADMA $(\mu \mathrm{mol} / \mathrm{L})$ & $0.452 \pm 0.058$ & $0.461 \pm 0.059^{*}$ & $0.454 \pm 0.057$ & $0.461 \pm 0.062$ & $0.413 \pm 0.029$ & $0.504 \pm 0.043^{\star *}$ \\
\hline Probable $\mathrm{SDB}^{\dagger}$ & $26(5.9)$ & $26(6.6)$ & $36(6.2)$ & $16(6.1)$ & $27(6.1)$ & $25(6.3)$ \\
\hline $\begin{array}{l}\text { Urinary sodium excretion } \\
\text { (mmol/night) }\end{array}$ & $51.2 \pm 27.2$ & $66.3 \pm 3.0^{\star *}$ & $53.7 \pm 28.0$ & $68.6 \pm 36.1^{\star \star}$ & $56.8 \pm 32.2$ & $59.8 \pm 30.6$ \\
\hline \multicolumn{7}{|l|}{ Circadian rhythm parameters } \\
\hline UME $(\mu \mathrm{g})$ & $6.8(4.2-10.5)$ & $6.1(3.9-9.5)^{\star}$ & $6.9(4.2-10.4)$ & $5.9(3.6-9.0)^{\star *}$ & $6.6(4.1-10.2)$ & $6.6(3.8-9.6)$ \\
\hline Bedtime (clock time) & $22: 30 \pm 1: 09$ & $22: 22 \pm 1: 10$ & $22: 27 \pm 1: 08$ & $22: 24 \pm 1: 12$ & $22: 34 \pm 1: 07$ & $22: 18 \pm 1: 11^{\star *}$ \\
\hline $\begin{array}{l}\text { Duration in bed (scotoperiod) } \\
\text { (min) }\end{array}$ & $492.9 \pm 73.1$ & $509.2 \pm 78.1^{\star *}$ & $496.3 \pm 74.6$ & $510.1 \pm 78.0^{*}$ & $487.9 \pm 72.1$ & $514.8 \pm 77.6^{\star *}$ \\
\hline $\begin{array}{l}\text { Day length (photoperiod) } \\
\text { (min) }\end{array}$ & $646(608-684)$ & $650(606-690)$ & $650(609-688)$ & $642(605-687)$ & $650(610-687)$ & $642(607-690)$ \\
\hline $\begin{array}{l}\text { Daytime physical activity } \\
\text { (counts/min) }\end{array}$ & $312.3 \pm 108.6$ & $284.0 \pm 101.4^{\star *}$ & $310.6 \pm 106.3$ & $273.2 \pm 101.5^{\star \star}$ & $309.3 \pm 105.8$ & $287.5 \pm 105.5^{\star \star}$ \\
\hline \multicolumn{7}{|l|}{ Ambulatory BP parameters } \\
\hline Daytime SBP (mmHg) & $128.8 \pm 12.3$ & $142.6 \pm 12.3^{\star \star}$ & $135.8 \pm 14.0$ & $134.1 \pm 14.4$ & $134.7 \pm 13.6$ & $136.0 \pm 14.6$ \\
\hline Daytime DBP $(\mathrm{mmHg})$ & $76.9 \pm 7.0$ & $83.0 \pm 7.3^{\star *}$ & $80.4 \pm 7.7$ & $78.4 \pm 7.7^{\star *}$ & $79.9 \pm 7.4$ & $79.7 \pm 8.1$ \\
\hline Night-time SBP (mmHg) & $104.6 \pm 8.9$ & $129.2 \pm 12.1^{\star \star}$ & $110.5 \pm 13.3$ & $128.8 \pm 14.9^{* *}$ & $115.4 \pm 15.9$ & $117.0 \pm 16.5$ \\
\hline Night-time DBP (mmHg) & $61.4 \pm 5.0$ & $73.9 \pm 6.5^{\star *}$ & $62.8 \pm 7.6$ & $72.7 \pm 7.8^{* *}$ & $67.5 \pm 8.4$ & $67.0 \pm 8.6$ \\
\hline Dipping (\%) & $18.3 \pm 7.7$ & $9.1 \pm 7.6^{\star \star}$ & $18.5 \pm 6.0$ & $3.8 \pm 5.5^{\star \star}$ & $14.2 \pm 8.9$ & $13.8 \pm 9.0$ \\
\hline
\end{tabular}

Data given as mean $\pm S D$, median (IQR), or $n(\%)$. ${ }^{*} P<0.05,{ }^{*} \mathrm{P}<0.01$ vs. each reference group. ${ }^{+}$Sleep efficiency $<70 \%$ and $/$ or total sleep time $<5 \mathrm{~h}$. ADMA, asymmetric dimethylarginine; BMI, body mass index; BP, blood pressure; DBP, diastolic blood pressure; eGFR, estimated glomerular filtration rate; $\mathrm{NH}$, nocturnal hypertension; SBP, systolic blood pressure; SDB, sleep-disordered breathing; UME, urinary 6-sulfatoxymelatonin excretion.

\section{Methods}

\section{Participants and Study Protocol}

A total of 880 elderly subjects voluntarily enrolled between September 2010 and March 2013 in a study titled "Housing Environments and Health Investigation among Japanese Older People in Nara, Kansai Region: A Prospective Communitybased Cohort (HEIJO-KYO) Study". Of these, 852 home-dwelling participants met the inclusion criteria of completed urinary 6-sulfatoxymelatonin excretion (UME) and ABP measurement records. All participants provided written informed consent, and the study protocol was approved by the medical ethics committee of Nara Medical University.

We previously reported our study protocols. ${ }^{20}$ In brief, we used a standardized questionnaire and personal interview to collect demographic and medical information and collected venous blood samples. Then, we initiated a 48-h ABP measurement from the 1st day noon to 3rd day noon, and instructed the participants to collect their urine the 2 nd night and maintain a standardized sleep diary by making a note of the time they went to bed and the period of time they spent in bed.

\section{Serum ADMA Measurement}

Venous blood samples were obtained in the morning after overnight fasting. The serum samples were collected after being centrifuged and stored at $-80^{\circ} \mathrm{C}$ until measurement. At a commercial laboratory (SRL Inc., Tokyo, Japan), high-performance liquid chromatography with a lower ADMA detection limit of $0.1 \mu \mathrm{mol} / \mathrm{L}$ was used to measure serum ADMA concentration. ${ }^{21}$ No sample had ADMA below the detection limit.

\section{UME Assessment}

The urine collection protocol involved discarding the last void at bedtime and collecting each subsequent void until rising time, including the first morning void. Samples were stored in dark bottles with a cold pack, the total volume was measured, and then the samples were stored at $-20^{\circ} \mathrm{C}$ until the assay. A highly sensitive enzyme-linked immunosorbent assay kit (RE54031; IBL International, Hamburg, Germany) with a lower 6-sulfatoxymelatonin detection limit of $1.0 \mathrm{ng} / \mathrm{ml}$ was used to measure urinary 6-sulfatoxymelatonin concentration. UME was calculated as follows: UME $(\mu \mathrm{g})=6$-sulfatoxymelatonin concentration $(\mu \mathrm{g} / \mathrm{ml}) \times$ total overnight urine volume $(\mathrm{ml})$. UME data were considered missing if the urine was not collected according to the protocol. Thirteen samples had 6-sulfatoxymelatonin below the detection limit, so the detection limit value was substituted.

\section{ABP Monitoring (ABPM)}

A validated ambulatory recorder (TM-2430; A\&D, Tokyo, 


\begin{tabular}{|c|c|c|c|c|c|c|}
\hline \multirow[b]{3}{*}{ UME quartiles $(\mu \mathrm{g})$} & \multicolumn{3}{|c|}{ NH } & \multicolumn{3}{|c|}{ Non-dipper } \\
\hline & Low ADMA & High ADMA & Overall & Low ADMA & High ADMA & Overall \\
\hline & & & & & & \\
\hline \multicolumn{7}{|l|}{$\mathrm{Q}^{\dagger}{ }^{\dagger}(<4.0)$} \\
\hline No. participants & 107 & 106 & 213 & 107 & 106 & 213 \\
\hline No. cases & 55 & 52 & 107 & 43 & 41 & 84 \\
\hline \multicolumn{7}{|l|}{ Q2 (4.0-6.6) } \\
\hline No. participants & 120 & 93 & 213 & 120 & 93 & 213 \\
\hline No. cases & 60 & 45 & 105 & 40 & 24 & 64 \\
\hline $\mathrm{OR}^{\ddagger}$ & 0.92 & 1.03 & 1.01 & 0.74 & 0.48 & 0.65 \\
\hline $95 \% \mathrm{Cl}$ & $0.53-1.60$ & $0.56-1.89$ & $0.67-1.52$ & $0.42-1.30$ & $0.25-0.93$ & $0.42-0.99$ \\
\hline \multicolumn{7}{|l|}{ Q3 (6.6-10.0) } \\
\hline No. participants & 107 & 106 & 213 & 107 & 106 & 213 \\
\hline No. cases & 44 & 55 & 99 & 28 & 35 & 63 \\
\hline $\mathrm{OR}^{\ddagger}$ & 0.57 & 1.10 & 0.81 & 0.51 & 0.68 & 0.61 \\
\hline $95 \% \mathrm{Cl}$ & $0.32-1.02$ & $0.61-1.99$ & $0.54-1.22$ & $0.28-0.93$ & $0.37-1.25$ & $0.40-0.93$ \\
\hline \multicolumn{7}{|l|}{ Q4 ( $\geq 10.0)$} \\
\hline No. participants & 117 & 96 & 213 & 117 & 96 & 213 \\
\hline No. cases & 45 & 44 & 89 & 24 & 29 & 53 \\
\hline $\mathrm{OR}^{\ddagger}$ & 0.48 & 0.86 & 0.65 & 0.40 & 0.55 & 0.48 \\
\hline $95 \% \mathrm{Cl}$ & $0.26-0.85$ & $0.46-1.63$ & $0.43-0.998$ & $0.21-0.75$ & $0.28-1.05$ & $0.30-0.75$ \\
\hline$P$ trend & 0.004 & 0.75 & 0.030 & 0.002 & 0.12 & 0.001 \\
\hline
\end{tabular}

†Reference category. ${ }^{\ddagger} \mathrm{NH}$ : adjusted for age (per 5 years), gender, BMI, current smoker, eGFR (per $10 \mathrm{ml} \cdot \mathrm{min}^{-1} \cdot 1.73 \mathrm{~m}^{-2}$ ), urinary sodium excretion (per $10 \mathrm{mmol}$ ), duration in bed (per $30 \mathrm{~min}$ ), and daytime physical activity (per $100 \mathrm{counts} / \mathrm{min})$. Non-dipper: adjusted for age (per 5 years), antihypertensive drug use, diabetes, eGFR (per $10 \mathrm{ml} \cdot \mathrm{min}^{-1} \cdot 1.73 \mathrm{~m}^{-2}$ ), urinary sodium excretion (per $10 \mathrm{mmol}$ ), duration in bed (per $30 \mathrm{~min}$ ), and daytime physical activity (per 100 counts/min). $\mathrm{Cl}$, confidence interval; OR, odds ratio. Other abbreviations as in Table 1.

Japan) and cuff on the non-dominant arm were used to perform ABPM. BP was measured at 30-min intervals for $48 \mathrm{~h}$. Night-time was defined as the period in bed given in the sleep diary entries. BP measured $<10$ times during daytime or $<5$ times during night-time, as the result of errors, were excluded from analysis. The mean of 2 days' data in night-time systolic $\mathrm{BP}(\mathrm{SBP})$ and diastolic BP (DBP) were used as parameters for night-time $\mathrm{BP}$. NH and daytime hypertension (DH) were defined as night-time $\mathrm{SBP} / \mathrm{DBP} \geq 120 / 70 \mathrm{mmHg}$ and $135 / 85 \mathrm{mmHg}$, and non-dipper was defined as $<10 \%$ fall in night-time SBP relative to daytime SBP, respectively. ${ }^{22,23}$

\section{Other Measurements}

Body mass index (BMI) was calculated as weight $(\mathrm{kg}) / \mathrm{height}$ $\left(\mathrm{m}^{2}\right)$. A questionnaire was used to evaluate current smoking status. Venous blood samples were analyzed to determine glycated hemoglobin ( $\mathrm{HbA1c}$ ), fasting plasma glucose, and creatinine concentration. Duration in bed for the scotoperiod was obtained from the individual's sleep diary. Day length for the photoperiod in Nara (latitude: $34^{\circ} \mathrm{N}$ ) from sunrise to sunset on measurement days was obtained from the National Astronomical Observatory of Japan website. ${ }^{24}$ An actigraph (Actiwatch 2; Respironics, PA, USA) on the non-dominant wrist was used to record physical activity at 1-min intervals for 2 consecutive days. Daytime physical activity was determined using Actiware version 5.5 (Respironics) as the average of activity counts during the out-of-bed period. Probable sleep-disordered breathing (SDB) was defined as sleep efficiency (total sleep time divided by duration in bed) $<70 \%$ and/or total sleep time (sleep time during the in-bed period) $<5 \mathrm{~h} .{ }^{25}$ Urinary sodium excretion during night-time was estimated based on urinary concentration of sodium $(\mathrm{mmol} / \mathrm{L})$ and urine volume $(\mathrm{ml})$.

\section{Statistical Analysis}

Variables with a normal distribution are reported as mean \pm SD, and variables with asymmetric distribution as median (IQR). The unpaired t-test and Mann-Whitney U-test were used to compare the mean and median, respectively. The chi-squared test was used for the comparison of categorical data. Variables, including age, gender, BMI, current smoking status, antihypertensive drug use (calcium channel blocker, angiotensin-converting enzyme inhibitor, angiotensin receptor blocker, diuretics, $\alpha$-blocker, and $\beta$-blocker), diabetes, estimated glomerular filtration rate (eGFR), probable SDB, urinary sodium excretion, bedtime, duration in bed (scotoperiod), day length (photoperiod), and daytime physical activity, were compared according to the night-time BP, dipping, and ADMA status. For data regarding $\mathrm{ABPM}$, bedtime, duration in bed, day length, and physical activity, the average of 2 consecutive days was used for analysis. Potential confounding factors were investigated on univariate comparisons that were significantly $(\mathrm{P}<0.05)$ associated with non-dipper and NH (Table 1). Logistic regression analysis and analysis of covariance (ANCOVA), respectively, were used to simultaneously adjust odds ratios (OR) for $\mathrm{NH}$ and non-dipper and the means of night-time SBP and dipping for confounding factors (Tables 2,3). Logistic regression and linear regression analysis, respectively, were used to evaluate trends in the association of quartiles of UME with OR for NH and non-dipper and means of nocturnal SBP and dipping. SPSS version 19.0 for Windows (IBM SPSS, Chicago, IL, USA) was used to perform statistical analysis, and 2-sided $\mathrm{P}<0.05$ was considered significant. 


\begin{tabular}{|c|c|c|c|c|c|c|}
\hline & \multicolumn{3}{|c|}{ Adjusted night-time SBP $(\mathrm{mmHg})^{\dagger}$} & \multicolumn{3}{|c|}{ Adjusted dipping (\%)‡ } \\
\hline & Low ADMA & High ADMA & Overall & Low ADMA & High ADMA & Overall \\
\hline No. participants & 451 & 401 & 852 & 451 & 401 & 852 \\
\hline \multicolumn{7}{|l|}{ UME quartiles $(\mu \mathrm{g})$} \\
\hline Q1 $(<4.0)$ & $117.3 \pm 1.5$ & $117.5 \pm 1.5$ & $117.0 \pm 1.0$ & $12.3 \pm 0.8$ & $12.3 \pm 0.8$ & $12.4 \pm 0.6$ \\
\hline Q2 (4.0-6.6) & $117.0 \pm 1.4$ & $117.1 \pm 1.5$ & $117.2 \pm 1.0$ & $13.4 \pm 0.8$ & $14.8 \pm 0.9$ & $13.8 \pm 0.6$ \\
\hline Q3 (6.6-10.0) & $113.6 \pm 1.4$ & $117.4 \pm 1.5$ & $115.4 \pm 1.0$ & $15.6 \pm 0.8$ & $13.7 \pm 0.8$ & $14.7 \pm 0.6$ \\
\hline Q4 ( $\geq 10.0)$ & $113.7 \pm 1.4$ & $115.9 \pm 1.6$ & $114.8 \pm 1.0$ & $15.3 \pm 0.8$ & $14.5 \pm 0.9$ & $14.9 \pm 0.6$ \\
\hline$P$ trend & 0.031 & 0.52 & 0.08 & 0.003 & 0.13 & 0.001 \\
\hline \multicolumn{7}{|l|}{ Continuous UME (log $\mu \mathrm{g})$} \\
\hline Regression coefficient & -2.784 & -1.304 & -1.816 & 1.825 & 0.955 & 1.357 \\
\hline $95 \% \mathrm{Cl}$ & -4.890 to -0.677 & -3.579 to 0.971 & -3.356 to -0.275 & 0.628 to 3.023 & -0.281 to 2.190 & 0.499 to 2.216 \\
\hline
\end{tabular}

Data given as mean \pm SE. ${ }^{\dagger}$ Adjusted for age (per 5 years), gender, BMI, current smoker, eGFR (per $10 \mathrm{ml}^{\prime} \mathrm{min}^{-1} \cdot 1.73 \mathrm{~m}^{-2}$ ), urinary sodium excretion (per $10 \mathrm{mmol}$ ), duration in bed (per $30 \mathrm{~min}$ ), and daytime physical activity (per 100 counts $/ \mathrm{min})$. $\neq$ Adjusted for age (per 5 years), antihypertensive drug use, diabetes, eGFR (per $10 \mathrm{ml} \cdot \mathrm{min}^{-1} \cdot 1.73 \mathrm{~m}^{-2}$ ), urinary sodium excretion (per $10 \mathrm{mmol}$ ), duration in bed (per $30 \mathrm{~min}$ ), and daytime physical activity (per 100 counts/min). Abbreviations as in Tables 1,2.

\section{Results}

The mean age of the participants was $72.1 \pm 7.0$ years, and 425 (49.9\%) were male. The median UME was 6.6 $\mu \mathrm{g}$ (IQR, 4.0 $10.0 \mu \mathrm{g})$, and the mean ADMA was $0.46 \pm 0.06 \mu \mathrm{mol} / \mathrm{L}$. The mean night-time SBP and dipping were $116.2 \pm 16.2 \mathrm{mmHg}$ and $14.0 \pm 9.0 \%$, respectively.

The NH group (night-time BP $\geq 120 / 70 \mathrm{mmHg}, \mathrm{n}=400$ ) had significantly higher age, BMI, ADMA, urinary sodium excretion, prevalence of male gender and current smoker; lower eGFR, UME, and daytime physical activity; and significantly longer duration in bed relative to the non- $\mathrm{NH}$ group (nighttime $\mathrm{BP}<120 / 70 \mathrm{mmHg}, \mathrm{n}=452$; Table 1 ). Compared with the dipper group (dipping $\geq 10 \%, \mathrm{n}=588$ ), the non-dipper group (dipping $<10 \%, n=264$ ) had significantly higher age and urinary sodium excretion, prevalence of antihypertensive drug use, and diabetes; lower eGFR, UME, and daytime physical activity; and longer duration in bed. The high-ADMA group (ADMA $\geq 0.46 \mu \mathrm{mol} / \mathrm{L}, \mathrm{n}=401$ ) had significantly higher age, significantly lower eGFR and daytime physical activity, and significantly later bedtime and longer duration in bed relative to the low-ADMA group (ADMA $<0.46 \mu \mathrm{mol} / \mathrm{L}, \mathrm{n}=451$ ).

In the low-ADMA group, crude $\mathrm{OR}$ for $\mathrm{NH}$ and non-dipper significantly decreased with a quartile increase in UME (crude OR for NH and non-dipper: Q1, 1.00 and 1.00; Q2, 0.95 and 0.74; Q3, 0.66 and 0.53; Q4, 0.59 and 0.38; $\mathrm{P}_{\text {trend }}=0.023$ and 0.001 , respectively; Figures $\mathbf{A}, \mathbf{C})$. In the high-ADMA group, however, crude OR for NH and non-dipper did not significantly change with a quartile increase in UME (Figures B,D). In addition, crude OR for DH did not differ across UME quartiles both in the low- and high-ADMA groups $\left(\mathrm{P}_{\text {trend }}=0.71\right.$ and 0.99 , respectively).

Adjusted $\mathrm{OR}$ for $\mathrm{NH}$ and non-dipper according to quartiles of UME are listed in Table 2. After adjustment for potential confounding factors, higher UME was significantly and inversely associated with OR for $\mathrm{NH}$ and non-dipper in the lowADMA group (adjusted OR for NH and non-dipper: Q1, 1.00 and 1.00; Q2, 0.92 and 0.74; Q3, 0.57 and 0.51; Q4, 0.48 and $0.40 ; P_{\text {trend }}=0.004$ and 0.002 , respectively) but not in the highADMA group ( $\mathrm{P}_{\text {trend }}=0.75$ and 0.12 , respectively). In the overall subject group $(n=852)$, higher UME was significantly and inversely associated with adjusted $\mathrm{OR}$ for $\mathrm{NH}$ and non-dipper ( $\mathrm{P}_{\text {trend }}=0.030$ and 0.001 , respectively).
These trends in the associations of UME with night-time BP and with dipping in the low-ADMA group were significant on continuous variable analysis (adjusted mean night-time SBP and dipping: Q1, $117.3 \mathrm{mmHg}$ and $12.3 \%$; Q2, $117.0 \mathrm{mmHg}$ and $13.4 \%$; Q3, $113.6 \mathrm{mmHg}$ and $15.6 \%$; $4,113.7 \mathrm{mmHg}$ and 15.3\%; Ptrend $=0.031$ and 0.003 , respectively; Table 3 ) but not in the high-ADMA group ( $\mathrm{P}$ trend $=0.52$ and 0.13 ; respectively). These associations between UME and dipping did not change in the multivariate models substituting each kind of antihypertensive drug for total antihypertensive drugs. The dose-response slope produced by substituting the means for age, BMI, urinary sodium excretion, duration in bed, and daytime physical activity; the proportion for gender and current smoking status; and the mean categorical number for eGFR into the multivariate regression formula in Table 3 (night-time SBP in the low ADMA group) indicated that an increase in UME from 4.1 to $10.2 \mu \mathrm{g}$ (from 25 th to 75 th percentile) was associated with a 2.5-mmHg decrease (95\% CI: $0.6-4.5 \mathrm{mmHg}$ ) in night-time SBP (from 116.6 to $114.1 \mathrm{mmHg}$ ).

\section{Discussion}

This study has shown that ADMA attenuates the association of melatonin secretion with circadian BP variability, including night-time BP and dipping, in the general elderly population. The key novel observation is that UME was significantly associated with BP variability in the low-ADMA group but not in the high-ADMA group. To the best of our knowledge, this is the first evidence of the possible interaction of serum ADMA with the association of melatonin with night-time BP and dipping in humans.

Potential mechanisms underlying the interaction of ADMA with the association of melatonin with night-time BP and dipping are suggested by the NO pathway. Although the mechanisms responsible for the effect of melatonin on the reduction of BP are not fully understood, previous evidence has suggested that melatonin increases cytosolic $\mathrm{Ca}^{2+}$ in endothelial cells and increases eNO bioavailability. ${ }^{9,10}$ eNO level is closely linked with other regulatory systems in the control of vascular tone and arterial BP. ADMA is an endogenous competitive inhibitor of NOS that controls eNO bioavailability and may offset an increase in eNO by melatonin. Previous experimental study using rats has reported results consistent with the present find- 

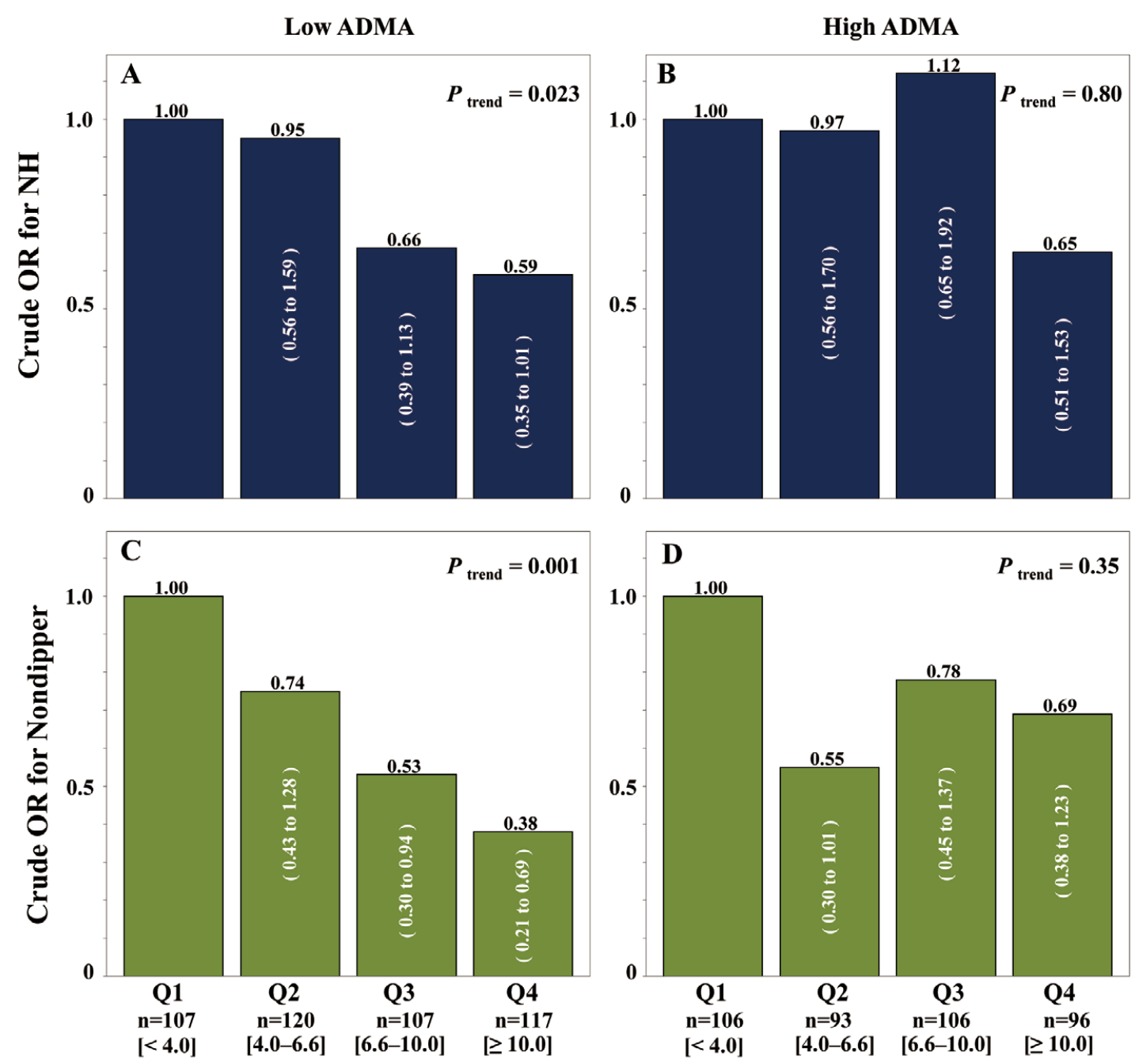

Urinary 6-sulfatoxymelatonin Excretion (range, $\mu \mathrm{g}$ )

Figure. Association of quartiles of urinary 6-sulfatoxymelatonin excretion with (A,B) nocturnal hypertension (NH) and (C,D) nondipper according to asymmetric dimethylarginine (ADMA) level. P-value determined on logistic regression analysis. Solid bars indicate OR and 95\% confidence interval (inside the bar). OR, odds ratio.

ings that exogenous melatonin could not significantly reduce $\mathrm{BP}$ under the condition of suppressed NOS by $\mathrm{N}_{\omega}$-nitro-Larginine methyl ester hydrochloride, an inhibitor of NOS. ${ }^{26}$ It remains unclear, however, whether pharmacological melatonin, which is considerably higher than endogenous melatonin, can sufficiently reduce night-time BP in humans with high serum ADMA.

The clinical implications of enhanced BP variability associated with melatonin secretion in individuals with low ADMA for total mortality can be interpreted using data from previous clinical trials and a meta-analysis of population-based prospective studies. In previous clinical trials, oral melatonin (2.5and 2-mg controlled release) significantly decreased night-time SBP by $6 \mathrm{mmHg} .{ }^{11,12}$ Pharmacological melatonin at these dosages is approximately 10-fold higher than endogenous melatonin. ${ }^{27}$ In the present study, 2.5-fold higher UME (from 25th to 75 th percentile) was significantly associated with a $2.5-\mathrm{mmHg}$ decrease in night-time SBP. A previous meta-analysis suggested that this $2.5-\mathrm{mmHg}$ decrease in night-time SBP associated with increased melatonin secretion (from 25 th to 75 th percentile) was predictive of decreased total mortality of $3.5 \% .^{1}$ Furthermore, $3.5 \%$ total mortality corresponds to approximately 34,000 annual deaths in the Japanese elderly population ( $\geq 60$ years of age). An additional epidemiological study with a longitudinal design is needed to better understand the effects of melatonin secretion on mortality.

Reduction of ADMA could be a possible therapeutic option for patients classified as non-dippers or having NH. Common atherosclerotic risk factors, such as aging, diabetes, and oxidative stress, may increase serum ADMA through inactivation of DDAH. ${ }^{19}$ In the present study, we observed the interaction of serum ADMA with the association of melatonin with nighttime $\mathrm{BP}$ and dipping in the high-ADMA group. Thus, the threshold for interactive action of ADMA on the association of melatonin with night-time BP and dipping may be considered to be not very high. Higher ADMA was associated with 
higher BP in the previous and present studies; ${ }^{28}$ therefore, increasing DDAH activity may be a possible therapeutic option for impaired BP variability in individuals with high ADMA. Some possible pathways that increase DDAH activity have been previously reported. ${ }^{29-31}$ Further research is required to understand the efficacy of decreasing ADMA for non-dipper and $\mathrm{NH}$.

The strength of the present study is the large sample size from which measurements of ADMA, UME, and ambulatory BP were made, which enabled the analysis of detailed categorical data (ie, 2 ADMA groups and 4 UME groups). We also identified a significant and positive association between UME and dipping on continuous data analysis. This is consistent with our previous report that the highest and the lowest levels of UME were observed in elderly individuals with extreme dipper and reverse dipper pattern, respectively, which were both risk factors for cardiovascular events. ${ }^{15}$ In contrast, an inverse association between UME and cardio-ankle vascular index, a marker of atherosclerosis, was reported. ${ }^{32} \mathrm{~A}$ future prospective study would clarify the association between endogenous melatonin level and cardiovascular events.

The limitations of the present study include lack of obstructive sleep apnea (OSA) measurements, an important condition that could impair endothelial function and decrease BP variability. ${ }^{33,34}$ In the present study, sleep quality was evaluated on actigraphy; and probable SDB defined on actigraphy (sleep efficiency $<70 \%$ and/or total sleep time $<5 \mathrm{~h}$ ), ${ }^{25}$ which is a predictor of SDB including OSA, did not significantly differ between the high- and low-ADMA groups. In addition, the associations of UME with NH and non-dipper in both ADMA groups were consistent in the models, including probable SDB as a covariate (data not shown). Some residual confounding effect of OSA, however, may exist. Another limitation included the lack of random selection from a nationally representative sample. The study participants were recruited from the local resident associations and elderly resident clubs, which may have caused selection bias. The generalizability of the present findings may be acceptable, however, because some basic data, such as BMI and eGFR, were similar to those of the national data in Japan. ${ }^{35}$

\section{Conclusions}

ADMA, an endogenous NOS inhibitor, attenuates the association of melatonin secretion with night-time $\mathrm{BP}$ and dipping in the general elderly population.

\section{Acknowledgments}

We would like to thank Sachiko Uemura and Naomi Takenaka for their valuable support during the collection of data.

Funding Sources: This work was supported by Grants from the Department of Indoor Environmental Medicine, Nara Medical University; Scientific Research from the Ministry of Education, Culture, Sports, Science and Technology; Mitsui Sumitomo Insurance Welfare Foundation; Meiji Yasuda Life Foundation of Health and Welfare; Osaka Gas Group Welfare Foundation; Japan Diabetes Foundation; Daiwa Securities Health Foundation; Japan Science and Technology Agency; and YKK AP.

\section{Disclosures}

None of the authors has any conflicts of interest to declare.

\section{References}

1. Boggia J, Li Y, Thijs L, Hansen TW, Kikuya M, Björklund-Bodegård $\mathrm{K}$, et al. Prognostic accuracy of day versus night ambulatory blood pressure: A cohort study. Lancet 2007; 370: 1219-1229.

2. Sega R, Facchetti R, Bombelli M, Cesana G, Corrao G, Grassi G, et al. Prognostic value of ambulatory and home blood pressures compared with office blood pressure in the general population: Follow-up results from the Pressioni Arteriose Monitorate e Loro Associazioni (PAMELA) study. Circulation 2005; 111: 1777-1783.

3. Fagard RH, Celis H, Thijs L, Staessen JA, Clement DL, De Buyzere ML, et al. Daytime and nighttime blood pressure as predictors of death and cause-specific cardiovascular events in hypertension. Hypertension 2008; 51: 55-61.

4. Verdecchia P, Schillaci G, Boldrini F, Guerrieri M, Gatteschi C, Benemio G, et al. Risk stratification of left ventricular hypertrophy in systemic hypertension using noninvasive ambulatory blood pressure monitoring. Am J Cardiol 1990; 66: 583-590.

5. Kario K, Pickering TG, Matsuo T, Hoshide S, Schwartz JE, Shimada $\mathrm{K}$. Stroke prognosis and abnormal nocturnal blood pressure falls in older hypertensives. Hypertension 2001; 38: 852-857.

6. Brzezinski A. Melatonin in humans. N Engl J Med 1997; 336: 186195.

7. Drew JE, Barrett P, Mercer JG, Moar KM, Canet E, Delagrange P, et al. Localization of the melatonin-related receptor in the rodent brain and peripheral tissues. J Neuroendocrinol 2001; 13: 453-458.

8. Ekmekcioglu C, Thalhammer T, Humpeler S, Mehrabi MR, Glogar HD, Hölzenbein T, et al. The melatonin receptor subtype MT2 is present in the human cardiovascular system. J Pineal Res 2003; 35: $40-44$.

9. Pogan L, Bissonnette P, Parent L, Sauvé R. The effects of melatonin on $\mathrm{Ca} 2+$ homeostasis in endothelial cells. J Pineal Res 2002; 33: $37-47$.

10. Arangino S, Cagnacci A, Angiolucci M, Vacca AM, Longu G, Volpe A, et al. Effects of melatonin on vascular reactivity, catecholamine levels, and blood pressure in healthy men. Am J Cardiol 1999; 83: $1417-1419$.

11. Grossman E, Laudon M, Yalcin R, Zengil H, Peleg E, Sharabi Y, et al. Melatonin reduces night blood pressure in patients with nocturnal hypertension. Am J Med 2006; 119: 898-902.

12. Scheer FA, Van Montfrans GA, van Someren EJ, Mairuhu G, Buijs RM. Daily nighttime melatonin reduces blood pressure in male patients with essential hypertension. Hypertension 2004; 43: 192-197.

13. Jonas M, Garfinkel D, Zisapel N, Laudon M, Grossman E. Impaired nocturnal melatonin secretion in non-dipper hypertensive patients. Blood Press 2003; 12: 19-24.

14. Zeman M, Dulková K, Bada V, Herichová I. Plasma melatonin concentrations in hypertensive patients with the dipping and nondipping blood pressure profile. Life Sci 2005; 76: 1795-1803.

15. Obayashi K, Saeki K, Iwamoto J, Okamoto N, Tomioka K, Nezu S, et al. Nocturnal urinary melatonin excretion is associated with nondipper pattern in elderly hypertensives. Hypertens Res 2013; 36: $736-740$.

16. Böger RH, Bode-Böger SM, Szuba A, Tsao PS, Chan JR, Tangphao $\mathrm{O}$, et al. Asymmetric dimethylarginine (ADMA): A novel risk factor for endothelial dysfunction: Its role in hypercholesterolemia. Circulation 1998; 98: $1842-1847$.

17. Zoccali C. Asymmetric dimethylarginine (ADMA): A cardiovascular and renal risk factor on the move. J Hypertens 2006; 24: 611619.

18. Lin KY, Ito A, Asagami T, Tsao PS, Adimoolam S, Kimoto M, et al. Impaired nitric oxide synthase pathway in diabetes mellitus: Role of asymmetric dimethylarginine and dimethylarginine dimethylaminohydrolase. Circulation 2002; 106: 987-992.

19. Cooke JP. Asymmetrical dimethylarginine: The Uber marker? Circulation 2004; 109: 1813-1818.

20. Obayashi K, Saeki K, Tone N, Kurumatani N. Relationship between melatonin secretion and nighttime blood pressure in elderly individuals with and without antihypertensive treatment: A cross-sectional study of the HEIJO-KYO cohort. Hypertens Res 2014; 37: 908-913.

21. Kobayashi S, Oka M, Maesato K, Ikee R, Mano T, Hidekazu M, et al. Coronary artery calcification, ADMA, and insulin resistance in CKD patients. Clin J Am Soc Nephrol 2008; 3: 1289-1295.

22. Ogihara T, Kikuchi K, Matsuoka H, Fujita T, Higaki J, Horiuchi $\mathrm{M}$, et al. The Japanese Society of Hypertension Guidelines for the Management of Hypertension (JSH 2009). Hypertens Res 2009; 32: $3-107$.

23. JCS Joint Working Group. Guidelines for the clinical use of 24 hour ambulatory blood pressure monitoring (ABPM) (JCS 2010): Digest version. Circ J 2012; 76: 508-519.

24. National Astronomical Observatory of Japan. Koyomi station. http:// eco.mtk.nao.ac.jp/koyomi/index.html.en (accessed April 1, 2014).

25. Mehra R, Stone KL, Ancoli-Israel S, Litwack-Harrison S, Ensrud $\mathrm{KE}$, Redline S. Interpreting wrist actigraphic indices of sleep in epidemiologic studies of the elderly: The study of osteoporotic fractures. Sleep 2008; 31: 1569-1576. 
26. Tain YL, Huang LT, Lin IC, Lau YT, Lin CY. Melatonin prevents hypertension and increased asymmetric dimethylarginine in young spontaneous hypertensive rats. J Pineal Res 2010; 49: 390-398.

27. European Medicines Agency. Circadian EPA Report. http://www. ema.europa.eu/docs/en_GB/document_library/EPAR_-_Scientific Discussion/human/000695/WC500026808.pdf (accessed April 1, 2014).

28. Kielstein JT, Bode-Böger SM, Frölich JC, Ritz E, Haller H, Fliser D. Asymmetric dimethylarginine, blood pressure, and renal perfusion in elderly subjects. Circulation 2003; 107: 1891-1895.

29. Pullamsetti SS, Savai R, Schaefer MB, Wilhelm J, Ghofrani HA, Weissmann N, et al. cAMP phosphodiesterase inhibitors increases nitric oxide production by modulating dimethylarginine dimethylaminohydrolases. Circulation 2010; 123: 1194-1204.

30. Jung CH, Lee WJ, Hwang JY, Lee MJ, Seol SM, Kim YM, et al. Vaspin increases nitric oxide bioavailability through the reduction of asymmetric dimethylarginine in vascular endothelial cells. PLoS One 2012; 7: e52346, doi:10.1371/journal.pone.0052346.
31. Holden DP, Cartwright JE, Nussey SS, Whitley GS. Estrogen stimulates dimethylarginine dimethylaminohydrolase activity and the metabolism of asymmetric dimethylarginine. Circulation 2003; 108: $1575-1580$.

32. Obayashi K, Saeki K, Kurumatani N. Association between urinary 6-sulfatoxymelatonin excretion and arterial stiffness in the general elderly population: The HEIJO-KYO cohort. J Clin Endocrinol Metab 2014; 99: 3233-3239.

33. Wolf J, Hering D, Narkiewicz K. Non-dipping pattern of hypertension and obstructive sleep apnea syndrome. Hypertens Res 2010; 33: 867-871.

34. Reriani MK, Flammer AJ, Jama A, Lerman LO, Lerman A. Novel functional risk factors for the prediction of cardiovascular events in vulnerable patients following acute coronary syndrome. Circ J 2012; 76: $778-783$.

35. Ministry of Health, Labour and Welfare. The National Health and Nutrition Survey Japan 2010. http://www.mhlw.go.jp/bunya/kenkou/ eiyou/h22-houkoku.html (accessed April 1, 2014) (in Japanese). 